\title{
Women, immigration, poverty and tuberculosis
}

\section{Donne, immigrazione, povertà e tubercolosi}

\author{
Lucio Casali ${ }^{1,2}$, Mariano E. Crapa ${ }^{3}$ \\ ${ }^{1}$ Malattie dell'Apparato Respiratorio, Università degli Studi di Perugia, Perugia \\ ${ }^{2}$ Direttore U. C. Malattie dell'Apparato Respiratorio, AO S. Maria, Terni \\ ${ }^{3}$ Titolare assegno di ricerca, Università degli Studi di Perugia
}

In December 2009 an information sheet [1] edited by $\mathrm{WHO}$ reported that, in 2008, 3.6 million women fell ill with tuberculosis (TB) and 700,000 women died from TB, including 200,000 with human immunodeficiency virus (HIV) and TB. TB is the $3^{\text {rd }}$ leading cause of death worldwide among women aged between 15 and 44 years. It should be noted that this range englobes both the reproductive and working age. TB is the $4^{\text {th }}$ leading cause of death among women aged 10-19 years in low income countries. Once infected, women of reproductive age are more susceptible to developing TB than men of the same age.

TB is the disease of poverty, affecting the most vulnerable groups of the world's population: more than half of TB-related deaths occur in Asia while the greatest TB burden as percentage of population is in Africa. Other factors closely connected to the social realities of low income countries, like malnutrition and food insecurity, can contribute to make the situation worse and other important factors like smoking or comorbidities such as diabetes can further increase the burden of TB.

The diffusion of the HIV epidemic has provoked a "feminization" of this infection with a great burden of HIV-associated TB. The frequent extension of TB to the reproductive organs in females can be a cause of infertility. In some countries such as Pakistan and Afghanistan more women with TB are detected than men. In some areas of the undeveloped world women with TB are discriminated against and stigmatized by their families and communities. The stigma is always extended to their children who are marginalized and forced to aban- don school.

These are some of the critical points that highlight the importance of looking at TB not only as a masculine disease. We must consider that the points mentioned above describe a situation where TB is the leading cause of "healthy years" lost among women in young age. In this framework, migration from low-income countries constitutes another dramatic aspect of the problem.

However other co-factors must be investigated, i.e. the possible presence of anemia that can be caused both by food restriction and iron deficiency and/or by parasitic infestations which contribute to microscopic blood loss in the stool [2]. Usually hypochromic and microcytic anemia coexist, so that, after having excluded a form of Mediterranean anemia, a conservative approach based on iron supplementation or an iron-rich diet is recommended. Of course any abnormality identified in the presence of stool ova and parasites needs to be treated as well. Should this approach fail it is then necessary to consider also the menstruation history and decide if and when to study the iron metabolism.

This and other situations co-exist in a context of deprivation, handicaps and poverty usually localized in specific areas of the world, but they are well recognizable also in ethnic minorities within wealthier communities where TB can appear in the five years after the arrival of immigrants [3]. WHO document stresses the fact that not only does the HIV/AIDS epidemic have a disproportionate impact on minorities, but poverty means as well overcrowding, poorly ventilated houses, malnutrition,

\footnotetext{
$\doteq$ Lucio Casali

Università degli Studi di Perugia, Dipartimento di Medicina Interna, Sezione Malattie dell'Apparato Respiratorio AO S. Maria U.C. Malattie dell'Apparato Respiratorio

Via T di Joannuccio 1, 05100 Terni, Italia

email: Icasali@unipg.it
}

Multidisciplinary Respiratory Medicine 2010; 5(6): 398-400 
social displacement, reduced accessibility to health care, lack of egalitarian participation in society and finally a lack of trust in the new system. In these areas women belong to a category that experiences longer delays in seeking care and this means increased suffering, more expenses and greater risk for the community.

Focusing on the overall process of migration [4] different stages can be identified. First, there is a preentry phase where the migrant brings with her/him the main health profile of the country of origin. The second phase is often one of transition in which migrants spend their time in places that are not yet the final destination. In this intermediate phase many unfavourable conditions can impact negatively on the migrant's health [5]. Finally, during the post-entry phase new problems arise, such as the process of adaptation to new modes of work and life that can negatively influence the migrant's health. This novel status is often repulsive for them and migrants experience real difficulties in finding access to health facilities.

Migratory TB may therefore be a mirror of all the problems connected to migration. Amongst other things the downward trend of incidence is interrupted by the re-emergence of TB among vulnerable populations, including those who are migrants from countries where TB is less well controlled [6-8]. Moreover, as already mentioned, TB in the foreignborn occurs in younger age and is associated with higher treatment default and worse outcome $[7,8]$ and the incidence of multi-drug resistant TB (MDRTB) and extensively drug resistant TB (XDR-TB) can be associated to the migration of people from countries with high prevalence of these forms.

The role of poverty particularly in a low income country like India has been well depicted and some important conclusions have been stressed [9]: three to four months of work time (the equivalent to 20$30 \%$ of annual household income) are typically lost due to TB. The cost is higher if patients have delayed seeking treatment and remain ill longer. The possible debts as a consequence may trigger sale of assets such as land and livestock causing a much higher level of poverty. All the family members may feel the effects of malnutrition, with repercussions on children's health. Children may be removed from school because they have to work to support the family wages and so about one fifth of school children in India discontinue their studies, contributing not only to cultural impoverishment but to perpetuating the vicious cycle of poverty in general. Women pay also an additional cost connected to pregnancy and delivery, especially in the peri-partum period. The incidence of TB during pregnancy is increasing both in developed and developing countries [10].

Tuberculosis is well known to be associated with immunorestitution disease in HIV patients when a reversal of immunodepression is achieved with a recovery of CD4+ lymphocyte counts [11]. Moreover a paradoxical response in the course of tuberculosis treatment has been reported also in
HIV negative patients [12]. Pregnancy, on the other hand, might be seen as an immunosuppressive process aimed to avoid natural rejection of the fetus, and an impairment of lymphocytes activity expressed by a negative response to intradermoreaction with tuberculin has been documented [13]. After delivery a rebound of lymphocytic activity is expected as early as $24 \mathrm{~h}$ after delivery [13]. Therefore it is possible that in this moment symptoms of active disease may arise. Peri-partum tuberculosis is defined as the acute deterioration or worsening of clinical symptoms of a pre-existing tuberculosis during pregnancy or as the onset of clinical symptoms of TB within one month after delivery. A meta-analysis based on the English language literature extending from 1966 to 2002 [14] showed that $93 \%$ of peri-partum TB was located in extra pulmonary sites, in $69 \%$ of cases in the central nervous system. Despite therapy, $38 \%$ of the patients died and $13.8 \%$ had residual functional deficits. The investigation did not involve the HIV patients. These disturbing data should prompt the attention of physicians to differentiate a simple peri-partum fever from TB. The presence of HIV coinfection significantly increases the risk of maternal and infant disease or death, especially in countries like India where both infections are highly prevalent [15]. In this context active screening and targeted isoniazid preventive therapy among women should be considered to prevent these dramatic events $[15,16]$.

Another point of concern is the presence of extra pulmonary TB (EPTB) in males and females. In USA, where many ethnicities are present and many people are foreign-born, the whole phenomenon has been evaluated on the basis of official data from 1993 to 2006 [17]. The authors analyzed both EPTB and pulmonary TB (PTB), and showed an increased association between EPTB and female sex, nonwhite race and/or ethnicity and foreign-born status. Other former studies were consistent with these results [18-20]. Moreover the authors demonstrated a disproportionately slower decrease in EPTB cases compared to PTB. EPTB is traditionally considered non diffusive, but it can be interpreted also as a possible source of PTB and EPTB as well as of disseminated TB, and contemporary HIV positivity is seen as a risk factor for disseminated TB [17].

Reconsidering the prevalence of TB in both sexes a recent report of the WHO [21] affirmed a ratio of $1.9 \pm 0.6$ between male and females as the worldwide notification rate, with values as high as 4.7 in Armenia and ratios below 1 very rare and related to small populations. This ratio refers to pratically all the classes of age in adulthood but does not seem to apply in children or younger adolescents. Apart from many other factors, amongst which bias of notification should be mentioned, a clear interpretation of the prevalence in males and women has not yet been given. Neyrolle and Quintana-Murci [22] tried to examine the relationship between sex steroids and the immune response to infections, on the basis of experimental data. In fact it has been reported that androgen deprivation leads to an in- 
crease in the absolute number of $\mathrm{T}$ lymphocytes in the peripheral lymph nodes [23] and invariant natural killer T (iNKT) cells from females produce more interferon (INF)- $\gamma$ than do the cells from males [22]. Estradiol administration can restore the production of INF- $\gamma$ in castrated mice and in those submitted to genetic ablation in estradiol receptors [23]. Other models of infection like those caused by Leishmania and Coxiella suggest that the protection is higher in females than in males owing to the possible role of estrogens [24] and estrogens have been demonstrated to increase the activity of the INF- $\gamma$ gene promoter [25]. In fact both innate and immune cells and $\mathrm{T}$ lymphocytes can express genetic receptors for steroid hormones which could modulate the response of these cells [26].

Examining the maps of the $\mathrm{WHO}$ regarding the dis-

\section{References}

1. WHO. Stop TB partnership 2009 Tuberculosis. Women and TB WHO. Dec 2009. www.stoptb.org/assets/documents/ resources/factsheets/womenandtb.pdf

2. Fischbacher C, Bhopal R, Patel S, White M, Unwin N, Alberti KG. Anaemia in Chinese, South Asian, and European populations in Newcastle upon Tyne: cross sectional study. BMJ 2001;322:958-959.

3. Figueroa-Munoz JI, Ramon-Pardo P. Tuberculosis control in vulnerable groups. Bull World Health Organ 2008;86:733-735.

4. E.C.D.C. Technical Report. Migrant health: background note to the ECDC in migration and infectious diseases in E.U. Stockolm July 2009 www.ecdc.europe.eu

5. Ho MJ. Migratory journeys and tuberculosis risk. Med Anthropol Q 2003;17:442-458.

6. Lienhardt C. From exposure to disease: the role of environmental factors in susceptibility to and development of tuberculosis. Epidemiol Rev 2001;23:288-301.

7. Jakubowiak WM, Bogorodskaya EM, Borisov SE, Danilova ID, Kourbatova EV. Risk factors associated with default among new pulmonary TB patients and social support in six Russian regions. Int J Tuberc Lung Dis 2007;11:46-53.

8. Falzon D, van Cauteren D. Demographic features and trends in tuberculosis cases in the European Region, 19952005. Euro Surveill. 2008;13:8075. Available online: http://www.eurosurveillance.org/ViewArticle.aspx? Articleld= 8075.

9. Kamolratanakul $P$, Sawert $H$, Kongsin S, Lertmaharit $S$, Sriwongsa J, Na-Songkhla S, Wangmane S, Jittimanee S, Payanandana V. Economic impact of tuberculosis at the household level. Int J Tuberc Lung Dis 1999;3:596-602.

10. Ormerod P. Tuberculosis in pregnancy and the puerperium. Thorax 2001;56:494-499.

11. Wendel KA, Alwood KS, Gachuhi R, Chaisson RE, Bishai WR, Sterling TR. Paradoxical worsening of tuberculosis in HIV-infected persons. Chest 2001;120:193-197.

12. Cheng VC, Ho PL, Lee RA, Chan KS, Chan KK, Woo PC, Lau SK, Yuen KY. Clinical spectrum of paradoxical deterioration during antituberculosis therapy in non-HIV-infected patients. Eur J Clin Microbiol Infect Dis 2002;21:803-809.

13. Covelli HD, Wilson RT. Immunologic and medical considerations in tuberculin-sensitized pregnant patients. Am J Obstet Gynecol 1978;132:256-259.

14. Cheng VC, Woo PC, Lau SK, Cheung CH, Yung RW, Yam LY, Yuen KY. Peripartum tuberculosis as a form of immunorestitution disease. Eur J Clin Microbiol Infect Dis 2003;22:313-317. tribution of male/female ratios for new smear-positive TB cases according to age-class, one can observe that the values tend to decline with the progression of age and this could indirectly prove that after menopause TB could become more aggressive in females. These and other hypotheses need to be carefully investigated in order to better disclose many secrets of this disease.

However, bearing in mind the above information, we believe that the best conclusion is to return to the principle expressed in Article 25 of the Universal Declaration of Human Rights released in 1948: "Everyone has the right to a standard of living adequate for health and wellbeing including food, clothing, housing, medical care and necessary social services and the right to security in the event of sickness".
15. Gupta A, Nayak U, Ram M, Bhosale R, Patil S, Basavraj A, Kakrani A, Philip S, Desai D, Sastry J, Bollinger RC; Byramjee Jeejeebhoy Medical College-Johns Hopkins University Study Group. Postpartum tuberculosis incidence and mortality among HIV-infected women and their infants in Pune, India, 2002-2005. Clin Infect Dis 2007;45:241249.

16. Mofenson LM, Laughon BE. Human immunodeficiency virus, Mycobacterium tuberculosis, and pregnancy: a deadly combination. Clin Infect Dis 2007;45:250-253.

17. Peto HM, Pratt RH, Harrington TA, LoBue PA, Armstrong LR. Epidemiology of extrapulmonary tuberculosis in the United States, 1993-2006. Clin Infect Dis 2009;49:1350-1357.

18. Rieder HL, Snider DE Jr, Cauthen GM. Extrapulmonary tuberculosis in the United States. Am Rev Respir Dis 1990;141:347-351.

19. Snider DE Jr. Extrapulmonary tuberculosis in Oklahoma, 1965 to 1973. Am Rev Respir Dis 1975;111:641-646.

20. Gonzalez OY, Adams G, Teeter LD, Bui TT, Musser JM, Graviss EA. Extra-pulmonary manifestations in a large metropolitan area with low incidence of tuberculosis. Int J Tuberc Lung Dis 2003;7:1178-1185.

21. WHO report 2009. Global tuberculosis control - epidemiology, strategy, financing. http://www.who.int/tb/publications/global_report/2009/en/

22. Neyrolles O, Quintana-Murci L. Sexual inequality in tuberculosis. PLoS Med 2009;6:e1000199.

23. Roden AC, Moser MT, Tri SD, Mercader M, Kuntz SM, Dong $\mathrm{H}$, Hurwitz AA, McKean DJ, Celis E, Leibovich BC, Allison JP, Kwon ED. Augmentation of $\mathrm{T}$ cell levels and responses induced by androgen deprivation. J Immunology 2004;173:6098-6108.

24. Gourdy P, Araujo LM, Zhu R, Garmy-Susini B, Diem S, Laurell H, Leite-de-Moraes M, Dy M, Arnal JF, Bayard F, Herbelin A. Relevance of sexual dimorphism to regulatory $T$ cells: estradiol promotes IFN-gamma production by invariant natural killer T cells. Blood 2005;105:2415-2420.

25. Janele D, Lang T, Capellino S, Cutolo M, Da Silva JA, Straub $\mathrm{RH}$. Effects of testosterone, 17beta-estradiol, and downstream estrogens on cytokine secretion from human leukocytes in the presence and absence of cortisol. Ann N Y Acad Sci 2006;1069:168-182.

26. Bouman A, Heineman MJ, Faas MM. Sex hormones and the immune response in humans. Hum Reprod Update $2005 ; 11: 411-423$. 